\title{
ANALISIS PENGARUH VARIASI JARAK DAN TINGGI STIK SPRINKLER TERHADAP KINERJA IRIGASI PADA LUAS LAHAN TERBATAS
}

\author{
I Dewa Gede Jaya Negara1), Syamsul Hidayat ${ }^{1)}$, I Wayan Yasa ${ }^{1)}$, dan \\ Ni Luh Ayu Aprilianti ${ }^{1)}$
}

1) Jurusan Teknik Sipil, Fakultas Teknik, Universitas Mataram, Nusa Tenggara Barat

jayanegara@unram.ac.id

\begin{abstract}
The conversion of agricultural land in urban areas has resulted in increasingly narrow agricultural land and many irrigation networks are not functioning. This has resulted in many isolated lands that cannot even be served by irrigation, so that the alternative source of agricultural water is local shallow ground well water. With the potential of water sources and limited land area, farming is expected to utilize water efficiently. Small sprinkler irrigation systems such as the 24D Netafim on the market, are expected to be an alternative in providing irrigation and for that it is necessary to test the ability of the irrigation system on the irrigation radius and its uniformity at a duration of 15 minutes. The test results showed that the irrigation uniformity was above $85 \%$ at the distance between sprinklers $4.5 \mathrm{~m}, 5 \mathrm{~m}$ and $5.5 \mathrm{~m}$ and $6 \mathrm{~m}$ with a stick height of $0.5 \mathrm{~m}$ and $0.75 \mathrm{~m}$. For stick heights of $1.0 \mathrm{~m}$ and $1.25 \mathrm{~m}$ at the same sprinkler distance, the uniformity coefficient is less than $85 \%$. While the optimal irrigation radius obtained at a sprinkler distance of $4.5 \mathrm{~m}, 5 \mathrm{~m}$ and $5.5 \mathrm{~m}$ is an average of $5.6 \mathrm{~m}$.
\end{abstract}

Keywords: distance, stick, radius

\begin{abstract}
ABSTRAK
Perubahan fungsi lahan pertanian di daerah perkotaan mengakibatkan luas lahan pertanian semakin sempit dan jaringan irigasi banyak yang tidak berfungsi. Hal tersebut mengakibatkan banyak lahan terisolir bahkan tidak dapat di layani oleh irigasi, sehingga sumber air pertanian yang menjadi alternatif adalah air sumur tanah dangkal setempat. Dengan adanya potensi sumber air dan luas lahan yang terbatas maka usahatani diharapkan dapat memanfaatkan air secara efisien. Sistem irigasi sprinkler kecil seperti $24 D$ Netafim yang ada dipasaran, diperkirakan dapat sebagai alternatif dalam pemberian irigasi dan untuk itu diperlukan uji tentang kemampuan sistem irigasi tersebut pada variasi jarak antara sprinkler dan tinggi stik terhadap radius irigasi dan keseragamannya pada durasi 15 menit. Hasil uji menunjukkan hasil keseragaman irigasi di atas $85 \%$ pada jarak antara sprinkle $4.5 \mathrm{~m}, 5 \mathrm{~m}$ dan $5.5 \mathrm{~m}$ dan $6 \mathrm{~m}$ dengan tinggi stik $0.5 \mathrm{~m}$ dan $0.75 \mathrm{~m}$. Untuk tinggi stik $1.0 \mathrm{~m}$ dan $1.25 \mathrm{~m}$ pada jarak sprinkler yang sama diperoleh koefisien keseragaman kurang dari $85 \%$. Sedangkan radius irigasi optimal diperoleh pada jarak sprinkler $4.5 \mathrm{~m}, 5 \mathrm{~m}$ dan $5.5 \mathrm{~m}$ adalah rata-rata sebesar $5.6 \mathrm{~m}$.
\end{abstract}

Kata kunci: jarak, stik, radius 


\section{PENDAHULUAN}

Indonesia disebut sebagai suatu negara agraris, dimana sebagian besar penduduknya bermata pencaharian pada sektor pertanian. Seiring dengan bertambahnya jumlah penduduk di Indonesia, khususnya di Pulau Lombok setiap tahunnya menyebabkan berkembang juga kebutuhan masyarakat, salah satunya adalah kebutuhan lahan. Alih fungsi lahan pertanian dari tahun ke tahun terus semakin bertambah, yang menyebabkan lahan pertanian semakin berkurang. Dengan terbatasnya luas lahan pertanian yang tersedia maka sistem irigasi yang digunakan sebelumnya, diperkirakan polanya sudah tidak memadai lagi untuk digunakan. Selain itu dengan meningkatnya perkembangan penduduk, menuntut agar produktivitas lahan pertanian harus tetap bisa dilakukan untuk mendukung ketersediaan pangan lokal. Untuk itu perlu sistem irigasi yang lebih sesuai untuk pertanian pada luas lahan terbatas, dan memanfaatkan sumber air yang tersedia secara efisien.

Semakin banyak lahan yang dipergunakan untuk pembangunan dan semakin sedikit lahan untuk pertanian apalagi di daerah perkotaan. Perkembangan pola hidup manusia dari tahun ke tahun menyebabkan berubahnya alih guna lahan. Alih guna lahan menyebabkan sulit ditemui lahan pertanian yang luas dan hanya menyisakan lahan sempit atau sedikit. Oleh karena itu, dalam meningkatkan produktivitas hasil pertanian dengan lahan yang terbatas diperkirakan dapat dibantu dengan penggunaan sistem irigasi mikro. Salah satu jenis irigasi mikro adalah irigasi sprinklers mini. Penggunaan sistem irigasi mikro dalam penerapannya tidak membutuhkan lahan yang besar, serta dapat memanfaatkan sumber air yang seadanya misalnya pada lahan kering (Marasi et al., 2014).

Dalam bidang pertanian, air merupakan salah satu kebutuhan utama tanaman. Setiap tanaman memiliki pertumbuhan yang berbeda-beda contohnya pada pertumbuhan tingginya. Pertumbuhan tanaman digunakan sebagai indikator untuk mengetahui karakteristik tanaman yang hubungannya dengan kebutuhan air tanaman.

Penelitian dengan 3 buah sprinkler mini 24D Netafim telah dilakukan Swandayani (2020), yang menyatakan hasilnya menunjukkan terjadinya overlaping pada saat sistem irigasi sprinkler yang diuji sehingga terdapat distribusi irigasi yang kurang merata.

Pernyataan tersebut mungkin kurang tepat, karena pada irigasi sprinkler kadang 
diperlukan overlapping irigasi antara sprinkler satu dengan yang lainnya untuk meningkatkan keseragaman. Tujuan overlapping adalah untuk meningkatkan kasil keseragaman irigasi itu sendiri. Akan tetapi pada uji sprinkler Meganet 24D Netafim ini, masih perlu pengujian karena pengaruh tinggi stik terkait erat dengan tinggi tanaman yang dapat diirigasi. Sedangkan untuk uji jarak sprinkler diperkirakan ada kaitannya dengan kemampuan luasan irigasi dan besarnya debit yang diperlukan jaringan irigasi tersebut.

Adanya sistem irigasi sprinkler mini seperti sprinkler mini 24D Netafim yang ada di pasaran, diperkirakan dapat membantu kegiatan irigasi tanaman pada luas yang terbatas. Sprinkler ini memiliki radius irigasi sekitar 5m-6m, sehingga berpotensi dan cocok digunakan untuk usahatani pada luas lahan yang terbatas. Oleh karena itu penelitian ini bertujuan untuk mengetahui besarnya nilai koefisien keseragaman irigasi dari sprinkler mini 24D Netafim pada variasi jarak dan tinggi stik sprinkler dengan durasi waktu 15 menit, termasuk juga untuk mengetahui radius irigasi yang optimum yang mungkin dapat untuk diaplikasikan ketanaman.

Memperhatikan perlunya sistem irigasi yang efisien untuk luas lahan pertanian yang terbatas, diperkirakan dengan uji variasi jarak dan variasi tinggi stik sprinkler 24D Netafim tertentu akan diperoleh kemampuan irigasi sprinkler yang baik. Dengan kemampuan sistem irigasi tersebut maka luas lahan irigasi yang mampu diairi dan jumlah sprinkler yang diperlukan akan diketahui.

\section{KAJIAN PUSTAKA}

\subsection{Irigasi Pancaran}

Menurut Nopianti (2015) bahwa pengaruh durasi dengan sistem irigasi sprinkler mini tiga nozzle terhadap kedalaman resapan ke dalam tanah mencapai $17 \mathrm{~cm}$ dalam durasi 1 jam dengan debit rata-rata 0.563 lt/dtk serta menghasilkan diameter basahan rata-rata 5.35 meter.

Negara et al. (2015) telah melakukan penelitian rigasi sprinkler mini pada lahan kering Pringgabaya Utara Kabupaten Lombok Timur dan hasil penelitiannya menyimpulkan bahwa keseragaman (CU) irigasi sprinkler mini tiga nozzle besarnya rerata diatas $70 \%$, tergolong baik dengan kedalaman capaian irigasi sekitar $0.3 \mathrm{~cm}-$ $7 \mathrm{~cm}$. Besar debit sprinkler mini rerata $0.023 \mathrm{~m}^{3} / \mathrm{dt}$ dengan radius irigasi $(\mathrm{rs})=2.6$ $\mathrm{m}$.

Menurut Negara et al. (2021) menyatakan bahwa hasil pengujian 
pengaruh variasi kemiringan pipa transmisi $10^{\circ}, 20^{\circ}, \quad 30^{\circ}$ dan $40^{\circ}$ terhadap keseragaman dan radius irigasi pancaran pipa perforasi menunjukkan hasil nilai keseragaman minimal $85 \%$ dan terbesar 91\%, dengan kemampuan pancaran irigasi perforasi terbesar $2.66 \mathrm{~m}$ dan $2.40 \mathrm{~m}$.

Penelitian tanah tahun 2009 menyatakan kelebihan irigasi sprinkler dapat menghemat air sampai 50\% dibandingakn cara gelontoran. Irigasi sprinkler. Meningkatkan balai efisiensi penggunaan air pada tanaman bawang dibandingkan dengan metode irigasi permukaan (Kumr et al., 2007).

Menurut Ridwan et al. (2014) yang telah membuat rancangan jaringan irigasi mikro dirancang mengaatakan bahwa, dengan jenis mini sprinklers model HADAR 7110 Inverted Rotor sebanyak 12 buah,diameter pembasahan $10.2 \mathrm{~m}$, dengan jarak antar lateral dan sprinkler $5 \mathrm{~m}$ x $5 \mathrm{~m}$. Kebutuhan air irigasi per aplikasi pemberian air adalah $26.25 \mathrm{~mm}$. Waktu pemberian irigasi maksimum 5.13 jam, dengan interval irigasi maksimum 5 harian. Tinggi Tekanan Total (TDH) yang diperlukan sebesar $28.66 \mathrm{~m}$. Pertimbangan pemenuhan kebutuhan TDH lebih besar, dipilih jenis pompa yang memiliki BHP sebesar $0.25 \mathrm{KW}$, debit pompa 1.25 liter/detik, dengan total head $60 \mathrm{~m}$.
Berdasarkan kajian tersebut di atas bahwa untuk uji sprinkler Meganet 24D Netafim debit pompa yang digunakan hanya sekitar 0.45 1/dt karena keterbatasan kemampuan jangkauan alat hanya $5 \mathrm{~m}-6$ m saja. Dengan kondisi tersebut tentunya luas basahan irigasi yang diperoleh juga akan lebih kecil dari pada pengujian tersebut di atas.

\subsection{Landasan Teori}

Pada perkembangan teknologi saat ini, pemberian air kepada tanaman semakin berkembang mulai dari penggenangan bebas sampai dengan menggunakan tenaga pembangkit. Salah satu cara dengan menggunakan tenaga pembangkit adalah irigasi dengan menggunakan alat pancar. Irigasi sprinkler adalah cara pemberian air kepada tanaman yang dilakukan dari atas tanaman berupa pemancaran dimana pemancaran itu menggunakan tenaga penggerak berupa pompa air. Prinsip yang digunakan system ini adalah memberi tekanan pada air dalam pipa dan memancarkan ke udara sehingga menyerupai hujan selanjutnya jatuh pada permukaan tanah (Sudjarwadi, 1987).

Dalam perancangan sistem irigasi curah, nilai CU yang dianggap baik adalah lebih besar dari $85 \%$. Rancangan irigasi mikro (seperti tetes dan sprinkler) dengan nilai keseragaman yang tinggi dapat 
mendukung upaya untuk melakukan penghematan air (konservasi air) dalam upaya pelestarian lingkungan (Barragan et al., 2010).

Tusi \& Lanya (2016), telah melakukan rancangan sprinkler portable yang telah dikembangkan memiliki spesifikasi: nozzle head sprinkler jenis sprinkler impact plactic dengan ukuran nozzle $4 \mathrm{~mm}$, tinggi total stick riser 1.3 meter dengan diameter $3 / 4$ ", pipa lateral elastis dengan diameter 2 " dan panjang 50 meter, pipa sub-main (manifold) dan pipa utama sebesar 2". Adapun pompa yang digunakan memiliki total head 55 meter dengan tenaga penggerak 5.5 HP, serta selang hisap 2". Sprinkler portable yang telah dikembangkan ini dapat beroperasi pada tekanan operasi 1 sampai dengan 4 bar untuk spasi sprinkler dan lateral $10 \mathrm{~m}$ x 10 m. Uji dilakukan pada lahan 0.10 ha -0.3 ha yang menunjukkan hasil debit sprinkler pada tekanan 1 bar adalah $0.12 \quad$ 1/s. Nilai keseragaman irigasi yang dihasilkan pada tekanan 1 bar sebesar $80 \%$. Untuk memperoleh nilai keseragaman irigasi lebih dari 85\%, maka disarankan penggunaan tekanan operasi minimal 2 bar.

Memperhatikan tinggi stik sprinkler yang digunakan pada sprinkler portable tersebut dan besarnya tekanan yang diperlukan, maka pada sprinkler mini meganet 24D Netafim besarnya adalah berbeda bahkan lebih rendah dari spesifikasi sprinkler tersebut. Dengan banyaknya jenis jenis alat sprinkler di pasaran, tentunya akan membutuhkan pengujian yang lebih spesifik agar keunggulan masing-masing sprinkler dapat diketahui, sebelum diaplikan ke tanaman.

Berikut ini adalah tabel tinggi tanaman tinggi beberapa tanaman yang mempunyai nilai jual yang cukup tinggi di pasaran yang bisa diaplikasikan dengan menggunakan sistem irigasi sprinkler.

Tabel 1. Variasi Tinggi Tanaman

\begin{tabular}{cc}
\hline Jenis Tanaman & Tinggi Tanaman $(\mathrm{cm})$ \\
\hline Cabai & $50-70$ \\
Tomat & $30-50$ \\
Porang & $100-250$ \\
Pakcoy & $15-30$ \\
Mentimun & $50-250$ \\
Kentang & 50 \\
Kacang panjang & 250 \\
Kedelai & $64-68$ \\
Kubis & $40-60$ \\
\hline
\end{tabular}

\subsection{Keseragaman Irigasi Sprinkler (CU)}

Koefisien keseragaman distribusi air irigasi dinyatakan dengan suatu parameter yang disebut koefisien keseragaman (uniformity coefficient, CU). Koefisien keseragaman (CU) dipengaruhi oleh hubungan antara tekanan, ukuran nozzle, spasing sprinkler dan kondisi angin. Koefisien keseragaman dapat dihitung 
dengan persamaan di bawah (Christiansen, 1942 dalam Negara et al., 2015):

$$
\begin{aligned}
\mathrm{CU} & =100 \% \cdot(1-\mathrm{D} \bar{y}) \\
\mathrm{D} & =\sqrt{\Sigma}(\mathrm{yi}-\overline{\mathrm{y}}) 2 \mathrm{n}-1 .
\end{aligned}
$$

dengan:

$$
\begin{aligned}
& \mathrm{CU}=\text { koefisien keseragaman }(\%) \\
& \mathrm{D}=\text { deviasi standar } \\
& \overline{\mathrm{y}}=\text { harga rata-rata observasi } \\
& \mathrm{yi}=\text { nilai tiap-tiap observasi } \\
& \mathrm{n}=\text { jumlah titik observasi }
\end{aligned}
$$

\subsection{Radius Irigasi (rs)}

Radius irigasi sprinkler merupakan luas basahan yang dapat dicapai irigasi sprinkler dan berbentuk lingkaran. Data ini diperlukan untuk mengetahui luas irigasi yang dapat dilayani oleh sistem sprinkler. Persamaan yang digunakan untuk menentukan luas basahan irigasi adalan sebagai berikut.

$$
\mathrm{A}=3.14 \times \mathrm{r}^{2}
$$

dengan:

$$
\begin{aligned}
& \mathrm{A}=\operatorname{luas}\left(\mathrm{m}^{2}\right) \\
& \mathrm{r}=\text { jari-jari lingkaran }(\mathrm{m})
\end{aligned}
$$

\subsection{Debit Air}

Untuk perhitungan debit dapat digunakan persamaan berikut:

$$
\begin{aligned}
& \mathrm{Q}=\mathrm{v} / \mathrm{t} \\
& \text { dengan: } \\
& \mathrm{Q}=\text { debit aliran }\left(\mathrm{m}^{3} / \text { detik }\right) \\
& \mathrm{v}=\text { volume tampungan wadah }\left(\mathrm{m}^{3}\right) \\
& \mathrm{t}=\text { waktu penampungan (detik). }
\end{aligned}
$$

\section{METODE PENELITIAN}

\subsection{Lokasi Penelitian}

Penelitian ini dilakukan pada lahan eks sawah yang ada di wilayah Kota Mataram yang masih kosong, sedangkan lahan disekitar lokasi uji telah menjadi perumahan baru. Pada lahan ini juga terdapat sumur air tanah dangkal yang digunakan sebagai sumber air dari lahan.

\subsection{Pelaksanaan Penelitian}

Secara garis besar langkah-langkah pelaksanaan penelitian adalah sebagai berikut:

1. Tahap persiapan;

2. Tahap perencanaan model fisik irigasi sprinkler;

3. Tahap pengujian awal;

4. Tahap pelaksanaan penelitian;

5. Tahap pengumpulan data;

6. Analisis data. 


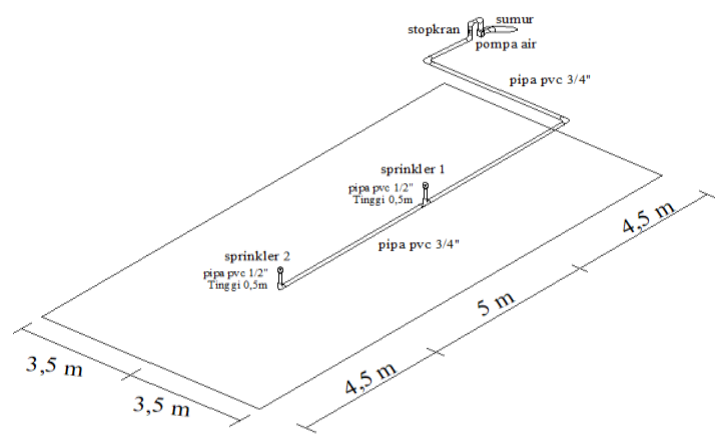

Gambar 1. Skema Jaringan irigasi Sprinkler Meganet 24D Netafim

\subsection{Alat dan Bahan Penelitian}

Peralatan yang digunakan dalam penelitian ini sebagai berikut:

1. Gergaji pipa, kamera dan meteran, ember dengan volume 4.6 liter dan alat tulis.

2. Gelas ukur $10 \mathrm{ml}$ digunakan untuk mengukur volume air irigasi pada uji keseragaman.

3. Sprinkler Meganet 24D Netafim seperti Gambar 2.

4. Gelas penampung volume air dengan diameter $6.2 \mathrm{~cm}$.

5. Stop watch untuk mencatat waktu.

6. Pompa air dan cok roll.

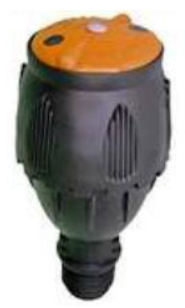

Gambar 2. Sprinkler Meganet 24D Netafim

Bahan yang digunakan dalam penelitian terdiri dari:
1. Air bersih dari sumur dangkal

2. Pipa pve $3 / 4$ inch dan $1 / 2$ inch

3. Sprinkler mini 2 buah

4. Stopkran 3/4 inch

5. Sambungan pipa (elbow, tee)

6. Seal tape dan lem pipa.

\subsection{Pelaksanaan}

Pelaksanaan penelitian dilakukan sebagai berikut:

1. Penyiapan lahan.

2. Penyiapan jaringan irigasi jarak dan tinggi stik sprinkler.

3. Penyiapan debit pompa.

4. Penyiapan variasi jarak dan tinggi stik sprinkler.

5. Pengujian dan pengukuran volume distri busi air irigasi yang tertampung pada mangkuk plastik dengan gelas ukur. Pengukuran ini hasil uji irigasi dilakukan sebanyak 3 kali dan hasilnya diambil satu sebagai nilai rata-rata dan data dicatat dari hasil rata-ratanya.

6. Data yang dikumpulkan pada setiap pengujian mencakup, data distribusi volume tampungan gelas plastic untuk perhitungan keseragaman irigasi $(\mathrm{CU})$, data panjang pancaran irigasi perforasi (L) dan tinggi. 
7. Analisis data uji dan pembahasan. Analisis data dilakukan terhadap keseragaman (CU), hubungan variasi jarak dan tinggi stik terhadap radius irigasi.

8. Hasil analisis data ditampilkan dalam bentuk tabel dan grafik serta dibahas, sedangkan penyimpulan hasil analisis dilakukan secara deskriptif

\section{HASIL DAN PEMBAHASAN}

\subsection{Analisis Debit Pompa}

Uji sprinkler dengan debit pompa Qp rata-rata $0.451 / \mathrm{dt}$ diperoleh hasil uji debit aliran masing-masing pipa sprinkler sebagai berikut. Pada jaringan sprinkler 1 diperoleh debit aliran 0.24 1/dt sampai 0.25 1/dt, sedangkan pada jaringan pipa sprinkler 2 debit alirannya adalah 0.17 sampai 0.20 1/dt. Debit tersebut adalah debit uji untuk semua variasi jarak dan tinggi stik sprinkler yang diuji.

\subsection{Keseragaman Irigasi Sprinkler (CU)}

Hubungan tinggi stik sprinkler dengan keseragaman irigasi untuk masingmasing variasi jarak dapat dilihat pada Gambar 3 sampai Gambar 6.

Berdasarkan hasil analisis grafik pada Gambar 3 diketahui bahwa besarnya nilai koefisien keseragaman irigasi sprinkler pada jarak antara stik $4.5 \mathrm{~m}$ dan tinggi stik $0.5 \mathrm{~m}$ diperoleh sebesar $86.557 \%$. Pada tinggi stik $0.5 \mathrm{~m}$ sampai 1 $\mathrm{m}$ nilai $\mathrm{CU}$ masih di atas angka $80 \%$. Sedangkan pada tinggi stik $1.25 \mathrm{~m}$ pada jarak antara sprinkler yang sama, diperoleh nilai CU sudah di bawah $80 \%$.

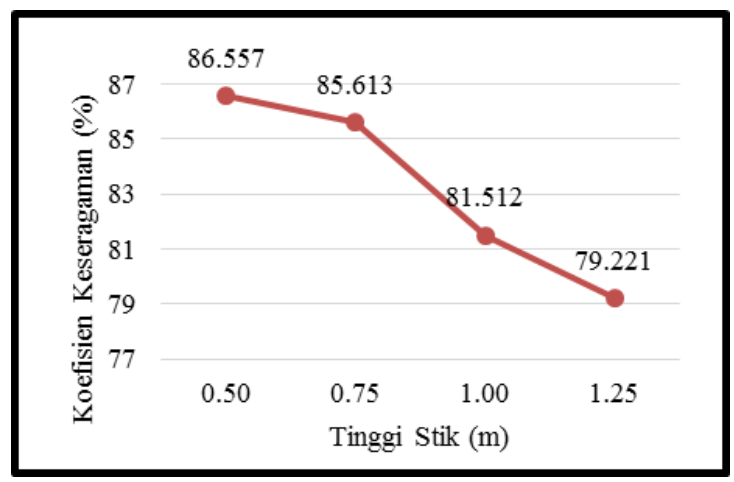

Gambar 3. Hubungan Koefisien

Keseragaman terhadap Tinggi Stik pada Jarak Sprinkler $4.5 \mathrm{~m}$

Tinggi stik $1.25 \mathrm{~m}$ diperoleh $\mathrm{CU}$ dibawah $80 \%$ yaitu sebesar $79.221 \%$. Keseragaman yang dihasilkan dalam uji sprinkler ini masih lebih baik dibandingkan dengan hasil uji pada Negara et al. (2015), yang hanya mampu di atas $70 \%$ saja dan mungkin nilai masih berkisar $70 \%$ sampai $80 \%$ saja. Dan berdasarkan hasil uji ini diketahui bahwa jarak antar stik juga sangat menentukan keseragaman irigasi yang dihasilkan.

Untuk uji dengan jarak antara sprinkler $5 \mathrm{~m}$ dapat dilihat pada gambar berikut. 


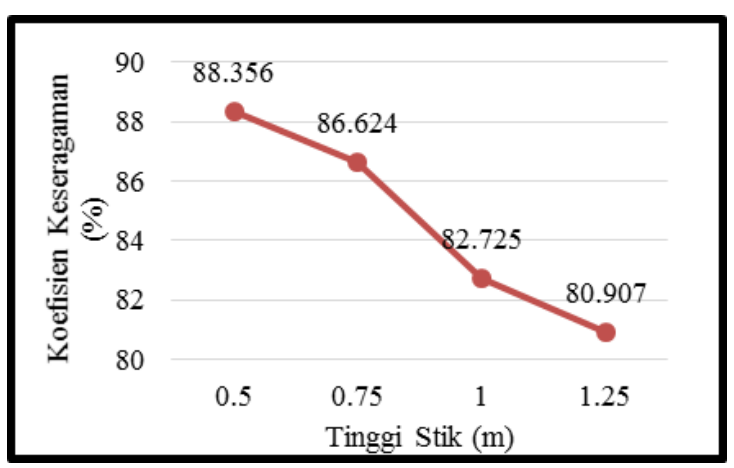

Gambar 4. Hubungan Koefisien Keseragaman terhadap Tinggi Stik dan Jarak Sprinkler 5 m

Grafik hubungan antara koefisien keseragaman dengan tinggi stik pada jarak antara sprinkler $5 \mathrm{~m}$ Gambar 4, menunjukkan bahwa nilai koefisien keseragaman terbesar yang dihasilkan adalah $88.36 \%$ pada tinggi stik $0.5 \mathrm{~m}$. Sedangkan nilai koefisien keseragaman terkecil diperoleh sebesar $80.907 \%$ pada tinggi stik $1.25 \mathrm{~m}$. Sehingga semakin tinggi stik yang digunakan maka semakin kecil nilai koefisien keseragamannya.

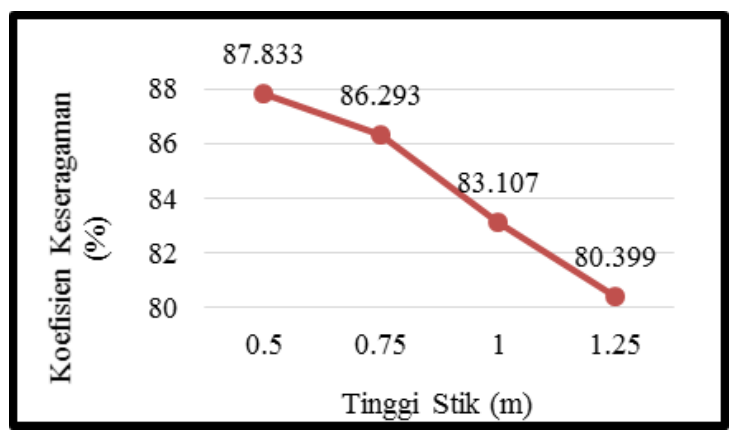

Gambar 5. Hubungan Koefisien Keseragaman Irigasi Sprinkler Terhadap Variasi Tinggi Stik dan Jarak 5.5 m

Berdasarkan hasil analisis pada Gambar 5 dengan jarak sprinkler $5.5 \mathrm{~m}$ terhada variasi tinggi stik, diperoleh nilai keseragaman irigasi terbesar $87.83 \%$ pada tinggi stik $0.5 \mathrm{~m}$. Sedangkan nilai $\mathrm{CU}$ terkecil diperoleh pada tinggi stik $1.25 \mathrm{~m}$ sebesar $80.49 \%$. Jadi hasil nilai CU uji sprinkler ini masih di atas $80 \%$ dan pada variasi jarak tersebut, keseragaman irigasi yang dihasikan akan menurun jika tinggi stik semakin tinggi.

Hasil uji sprinkler pada variasi jarak 6 m dapat dilihat pada Gambar 6.

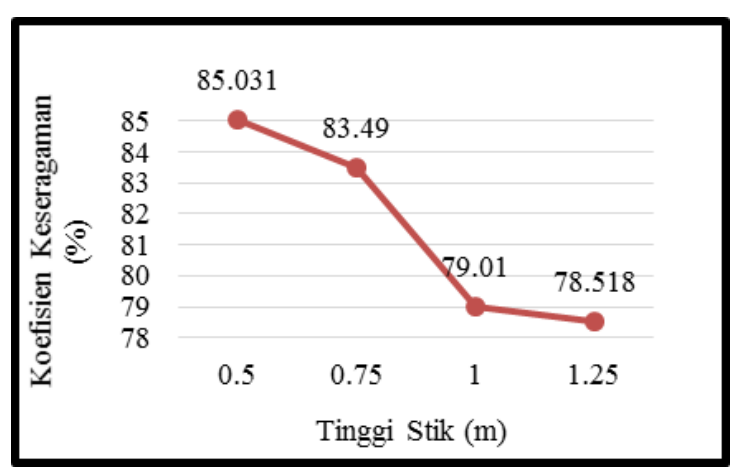

Gambar 6. Hubungan Koefisien Keseragaman terhadap Variasi Tinggi Stik dan jarak Sprinkler 6 m

Berdasarkan hasil analisis pada grafik Gambar 6 di atas diketahui bahwa, nilai koefisien keseragaman (CU) terbesar yang diperoleh adalah $85.031 \%$ dan nilai CU terendah 78.518\%. Berdasarkan hasil tersebut bahwa pada tinggi stik sprinkler 1 $\mathrm{m}$ dan $1.25 \mathrm{~m}$ nilai $\mathrm{CU}$ sudah dibawah $80 \%$, diperkirakan jarak tersebut sebagai batas yang tidak perlu digunakan untuk aplikasi irigasi karena distribusi air irigasi akan tidak merata dan perlu dihindari. 


\subsection{Radius Irigasi Sprinkler}

Hasil analisis radius pancaran irigasi dilakukan dengan pengoperasian dua sprinkler bersamaan dan di ukur radius pancaran terjauh dari masing-masing sprinkler sebanyak masing-masing 3 kali. Pola sebaran atau radius pancaran irigasi sprinkler Meganet 24D Netafim yang digunakan dapat dilihat pada Gambar 7 berikut:

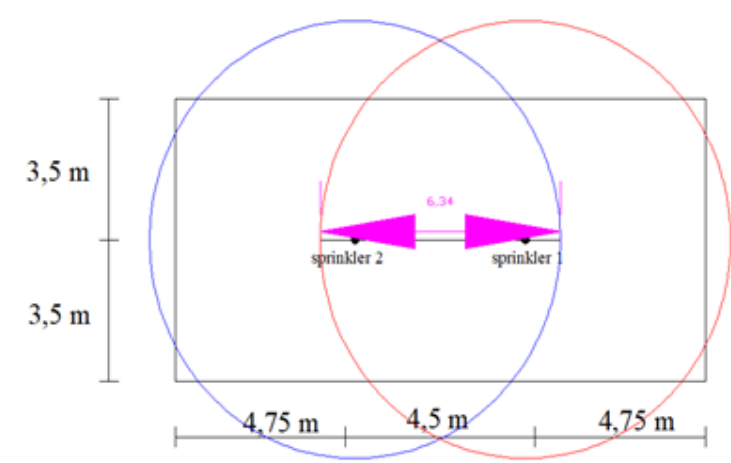

Gambar 7. Radius Pancaran Irigasi Sprinkler pada Jarak antar $4.5 \mathrm{~m}$ dan Tinggi Stik $0.5 \mathrm{~m}$

Grafik hasil analisis hubungan variasi tinggi stik terhadap jarak pancar irigasi dapat dilihat pada Gambar 8 berikut ini:

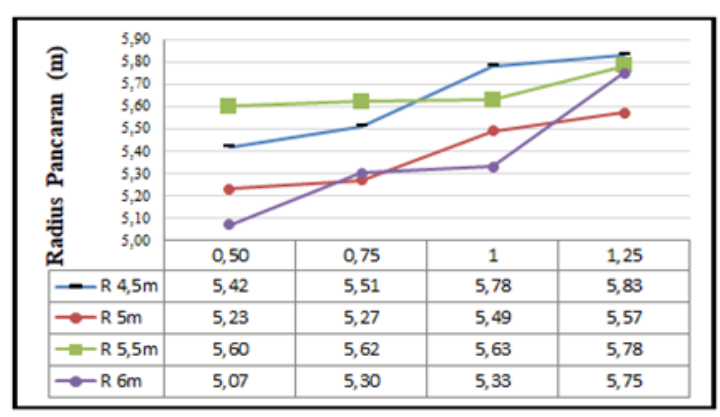

Gambar 8. Hubungan Variasi Tinggi Stik dan Jarak antar Sprinkler terhadap Radius Irigasi
Pada Gambar 8 terlihat bahwa radius pancaran yang dihasilkan pada berbagai variasi jarak antar sprinkler dan tinggi stik menunjukkan bahwa, pada debit yang digunakan semakin tinggi stik yang digunakan maka radius pancarnya akan semakin jauh dan sebaliknya. Selain hal tersebut yang perlu menjadi perhatian adalah tidak semua radius irigasi sprinkler yang dihasilkan memiliki keseragaman yang tinggi, sehingga yang menjadi patokan adalah nilai keseragaman yang tinggi untuk mendukung aplikasi ke tanaman tertentu. Akan tetapi bila dibandingkan dengan hasil uji irigasi pancar dengan pipa perforasi maka keseragaman irigasi sprinkler Meganet 24D Netafim ini masih lebih rendah dari irigasi perforasi yang besarnya di atas $85 \%$ sampai 91\% Negara et al. (2021). Akan tetapi bila diltinjau dari hasil pancarannya maka pancaran irigasi perforasi hanya mampu mencapai $2.66 \mathrm{~m}$ saja, sedangkan sprinkler mini mampu mencapai $5.6 \mathrm{~m}$ dengan kemampuan irigasi yang lebih luas.

\section{SIMPULAN DAN SARAN}

\subsection{Simpulan}

Keseragaman irigasi nilainya di atas $85 \%$ diperoleh pada jarak antara sprinkler $4.5 \mathrm{~m}$ sampai dengan $6 \mathrm{~m}$ pada tinggi stik $0.5 \mathrm{~m}$ dan $0.75 \mathrm{~m}$. Sedangkan pada jarak antara sprinkler $4.5 \mathrm{~m}$ sampai dengan $6 \mathrm{~m}$ 
dengan tinggi diatas 0.75 koefisien keseragaman irigasi yang diperoleh sudah kurang dari $85 \%$.

\subsection{Saran}

Untuk jarak dan tinggi sprinkler yang menghasilkan keseragaman di bawah $85 \%$, perlu dilakukan uji lebih lanjut dengan debit pompa yang lebih besar agar diketahui kemampuan alat tersebut secara optimal.

\section{DAFTAR PUSTAKA}

Ardhigunawan \& Negara, I D. G. J. (2010). Analisis Kinerja Sprinkler Mini terhadap Jarak Pancaran dan Estimasi Kedalaman Capaian Irigasi. Spektrum Sipil Jurnal Keilmuan dan Aplikasi Teknik Sipil, 1 (3), 163-238.

Barragan, J., Cots, L., Monserrat, J., Lopez, R., \& Wu, I. P. (2010). Water distribution uniformity and scheduling in micro-irrigation systems for water saving and environmental protection. Biosystems engineering, 107(3), 202211.

Iskandar, A.Y. (2014). Kajian Kriteria Mutu Air Irigasi. Jurnal Irigasi, 9 (1), 1-15.

Israelsen \& Stringham, G. E. (1992). Dasar-Dasar dan Praktek Irigasi. Jakarta: Erlangga.

Negara, I D G. J., Saadi, Y., \& Putra, I B. G. (2015). Karakteristik Kinerja Irigasi Sprinkler Mini Pada Lahan Kering Pringgabaya Utara Kabupaten Lombok Timur. Spektrum Sipil Jurnal Keilmuan dan Aplikasi Teknik Sipil, 2(2), 28-37.

Negara, I. D. G. J., Putra, I B. G.,
Supriyadi, A., \& Dewi, M .A. (2020). Analisis Kinerja Sprinkler Meganet 24 D Netafim Terhadap Variasi Debit Dan Jarak Penempatan. Seminar Nasional Saintek LPPM Universitas Mataram, Mataram

Negara, I D. G. J., Saidah, H., Yasa, I W., \& Halim, A. P. (2021). Keseragaman dan Pancaran Irigasi Pipa Perforasi pada Berbagai Kemiringan Pipa Transmisi. PADURAKSA, 10 (1).

Nopianti (2015). Analisa Pengaruh Pemberian Air Irigasi Sprinkler Mini dan Penggenangan Terhadap Kedalaman Resapan Dan Luas Basahan Pada Lahan Kering Pringgabaya. Skripsi. Mataram: Universitas Mataram,

Ridwan, D., Prasetyo, A. B., \& Joubert, D. M, (2014). Desain Jaringan Irigasi Mikro Jenis Mini Sprinkler. Journal Irigasi, 9 (2), 96-107.

Sheikhesmaeili, O., Montero, J., \& Laserna, S. (2016). Analysis of water application semi-portable big size sprinkler irrigation with systems in semi-arid areas. Agricultural Water Management, 163, 275-284.

Triatmodjo, B. (2012). Hidraulika I. Yogyakarta: Beta Offset.

Triatmodjo, B. (2013), Hidraulika II, Edisi II. Yogyakarta: Beta Offset.

Tusi, A., \& Lanya, B. (2016). Of Portable Sprinkler for Pakchoy Plant. Jurnal Irigasi, 11 (1), 43-54.

Utami, S. N. M. D. (2020). AnalisisVariasi Debit Pompa Terhadap Kinerja Sistem Irigasi Sprinkler Mini Meganet 24D Netafim Untuk Mendukung Usaha Pertanian Di Daerah Perkotaan. Skripsi. Mataram: Universitas Mataram. 